\title{
COMPARATIVE EDUCATION AND RESEARCH CAPACITY BUILDING: REFLECTIONS ON INTERNATIONAL TRANSFER AND THE SIGNIFICANCE OF CONTEXT
}

\author{
Michael Crossley ${ }^{1}$ \\ Research Centre for International and Comparative Studies \\ Graduate School of Education, University of Bristol
}

\begin{abstract}
Recent years have seen a resurgence of interest in comparative and international education, along with a fundamental reconceptualisation of this distinctive multidisciplinary field of study. The nature and significance of these developments are explored with particular reference to their implications for broader research capacity building initiatives worldwide. In doing so, a critique of the international transfer of globally dominant research modalities and strategies is presented - along with arguments for increased attention to context sensitivity in both international development cooperation and educational research in general. Illustrative examples that support these arguments are drawn from the author's own research, from an analysis of emergent educational policy debates in the UK, and from related studies being carried out in Malaysia. In concluding, the strategic role of comparative research traditions and perspectives in a rapidly globalizing world is highlighted, while supporting the promotion of new initiatives and research centres for comparative and international education.
\end{abstract}

\section{Historical Foundations}

Comparative and international education has a long and distinguished history in the western academic literature, with writers identifying the seminal $19^{\text {th }}$ century work of the French scholar Marc-Antoine Jullien as the foundational benchmark (Fraser, 1964; Jullien, 1817). Indeed, Jullien is often seen as the 'father' of comparative education for his first use of the term, and for his efforts to apply systematic research on foreign education systems to help shape the reform, and competitiveness, of education in France itself. This is a familiar rationale for change, and one that continues to influence the fact-finding travels, deliberations and initiatives of many education policymakers to the present day. Reflecting the scientific spirit that characterized early $19^{\text {th }}$ Century Europe, Jullien argued that detailed, statistically informed research on aspects such as student enrolments and standards, teacher recruitment and performance, administrative procedures and the financing of education would help 'to deduce true principles and determined routes so that education would be transformed into an almost positive science' (1817, cited in Fraser 1964, p.20). Today, the positivistic spirit and nature of Jullien's 'plan' can be seen in the statistical work of many international organizations and in the large-scale cross national comparative studies of educational achievement that have come to command the global attention of policy-makers and the general public alike. The influence of UNESCO's annual Education for All (EFA) Global Monitoring Reports is, for example, well documented by national and international education agencies, as many systems adjust their priorities and work towards the agreed EFA and Millennium Development Goals (MDG) and targets, that are currently set for 2015 (UNESCO, 2009). The visibility of large-scale cross-national studies of student achievement is even more dramatic, with the influence of those pioneered by the International Association for the Evaluation of Educational Achievement (IEA) (see Postlethwaite, 1999), being extended by the worldwide impact of the findings of the more recent OECD, Programme for International Student Assessment (PISA) surveys (OECD reports 2001, 2004, 2007, 2010). Researchers such as Grek et al. (2009) go so far as to suggest that such comparative surveys are increasingly steering the trajectories of educational systems worldwide as a new, and questionable, form of policy initiator and driver.

In the UK, the historical foundations of comparative and international education can be traced back to work Sir Michael Sadler carried out at the outset of the $20^{\text {th }}$ Century (Higginson, 1979). Sadler's influence upon the emergent field was, however, very different to that of Jullien - representing distinctively socio-cultural and interpretivist

1

${ }^{1}$ Correspondence can be directed to: m.crossley@bristol.ac.uk 


\section{MiCHAEL CROSSLEY}

paradigmatic perspectives and principles. Sadler challenged the scientific aspirations embodied in Jullien's search for the 'best' way forward for education. This prioritized greater attention to contextual differences and inspired the development of a more philosophically and historically informed tradition for comparative and international studies in education. In doing so, the work of Sadler, and of influential scholars such as Isaac Kandel (1933) who built upon his foundation, increasingly challenged the uncritical international transfer of educational policies and practices. This is well captured in the frequently quoted words of Sadler. As long ago as 1900, he argued that:

We cannot wander at pleasure among the educational systems of the world, like a child strolling through a garden, and pick off a flower from one bush and some leaves from another, and then expect that if we stick what we have gathered into the soil at home, we shall have a living plant (Sadler, 1900, quoted in Higginson, 1979, p.49).

Also pertinently for this present analysis, Sadler's work drew attention to the multidisciplinary nature of comparative and international education by emphasizing that:

In studying foreign systems of education, we should not forget that the things outside the schools matter even more than the things inside the schools, and govern and interpret the things inside (ibid).

Similarly, Kandel:

...relied heavily on qualitative rather than statistical studies in his comparative work. His examination of a nation's education system, political framework, history, sociology and philosophy showed how such extra school forces and factors could lead to either innovation in education or to extreme reliance on traditional practices (Pollack, 1993, p 2).

Such thinking clearly challenged the more positivistic traditions that had developed within the early history of this field of study, and generated tensions between different approaches to comparative research that continue to the present day. The following sections of this article briefly explore how comparative and international research in education has been both advanced and reconceptualised since these initial foundations. The analysis then revisits the issue of international transfer as it applies to the increasing globalization of dominant research modalities, and to related implications for research capacity building and international development co-operation.

\section{The Revitalisation and Reconceptualisation of Comparative and International Education}

The growth of the field of comparative education, and of its symbiotic relationship with what some scholars define as 'international education', is examined in detail elsewhere (Crossley \& Watson, 2003, 2009). For present purposes, however, it is significant to note that the 1960s and 1970s are recognized as a 'golden age' in terms of comparative education's popularity and influence in educational studies in the UK and other Western nations. The influence of the socio-cultural paradigm increased along with the emergence of a diversity of alternative theoretical and methodological approaches to research across the social sciences - including critical theory and postmodern and postcolonial perspectives. The influence of quantitative, statistical methodologies also remained strong, however, and the 'paradigm wars' of the 1960s and 1970s were clearly visible within this multidisciplinary field. This is evidenced by the tensions and debates surrounding the publication of Brian Holmes's (1965) arguments articulating a neo-positivistic, problem-based approach to comparative education - and the impact of the American text, Toward a Science of Comparative Education, published by Noah and Eckstein (1969). By the mid 1970s these buoyant times began to fade in the UK in the face of changes in the political and economic contexts of the day. Funding cuts to teacher education played a significant part in this decline as university and college courses in many foundational disciplines - including comparative education - were reduced in number in favour of '...the development of specific teaching competencies...that are related to actual performance in the classroom' (O'Sullivan, 2008, p.138). This was the start of the 'practical turn' that challenged, and continues to challenge, many of the disciplines of education, within and beyond the UK, to the present day (see Furlong \& Lawn, 2011). McGrath captures this well by saying:

In the educational sphere, globalization leads to the hegemony of the view that education is about economic competitiveness. This privileges human resources over liberal or critical perspectives of education and privileges the market over all other areas... The stress is on essential competencies and, as can be seen from the curriculum of teacher training across Britain, non-essential perspectives (historical, religious, international) are marginalized or ignored (2001, p.392).

Within the field itself, criticism emerged relating to a perceived preoccupation with the nation-state as the 


\section{COMPARATIVE EdUCATION AND RESEARCH CAPACITy BUILDING}

primary unit of analysis, with the descriptive nature of much work, and with a restrictive focus upon comparisons of policy in ways that overlooked the realities of practice in real educational contexts.

In response to these challenges, new generations of scholars recognized how a revitalisation of the field was emerging that emphasized its research potential in a rapidly globalising world. This revitalisation was spurred on by increased interest in, for example, multi-level forms of analysis, in-depth qualitative studies of teachers and learners in practice, grounded analyses of the implementation of educational policy in diverse contexts, the intensification of globalisation, and post-colonial interrogations of international development processes and agencies (Bray \& Thomas, 1995; Crossley \& Vulliamy, 1997; Crossley \& Tikly, 2004). Throughout the 1990s and early 2000s, this revitalisation was visible in an increase in the number of national comparative and international education societies, in the growth of the World Council for Comparative Education Societies (WCCES), and the emergence of new research journals and dedicated research centres (see Masemann, Bray \& Manzon, 2007). In addition, new constituencies of stakeholders began to express an interest in the findings of comparative research in education and in the implications of the increasingly prominent international studies of student achievement carried out by bodies such as the IEA and OECD. As already indicated, policy-makers, parents, and other stakeholders began to be influenced by the proliferation of local, national, and international league tables - and this, in itself, generated renewed interest in their methodological and theoretical foundations.

Today, the field of comparative and international education is, therefore, very different from the descriptive, nation-state and teacher education focused activity that once characterized much work within the international constituency. Leading centres in the field are now distinctly research oriented, making significant contributions to innovative forms of empirically grounded and theoretically informed analyses of contemporary educational and international development issues and problems. As detailed elsewhere, a fundamental 'reconceptualisation' (Crossley, 1999) has taken place. This continues to be inspired by engagement with new research paradigms, the new geo-politics of the $21^{\text {st }}$ Century, new technologies and new challenges.

In the following sections of this article, it is argued that one of the most significant challenges facing the future of comparative and international research in education relates to the very nature of educational and social research itself, and to ways in which this is connected to the building of, and the current international transfer of, research cultures, paradigms, and modalities. In doing this, it is argued that while much has, indeed, changed in recent decades, concern with context sensitivity and the processes of international transfer continue to lie at the heart of much disciplined comparative and international research in education. In many cases, this relates to familiar forms of the uncritical international transfer of educational policy and practice, as illustrated by my own early studies of the inappropriate exportation of school-based curriculum development from Australia and the UK to the very different context of Papua New Guinea (Crossley, 1984). More recent research by writers such as Beech (2006) and Rappleye (2011), however, revisits the education policy transfer literature in new and innovative ways, pointing to wider theoretical implications.

This present article also moves beyond the traditional educational transfer literature and debate. Here, therefore the focus is not upon the transfer of substantive policies and practices, but upon dilemmas generated by uncritical international transfer relating to the processes of educational research. This incorporates an analysis of the nature of research capacity building, an original critique of the use of research to identify 'best practice', and critical reflections upon the selective application of international studies of student achievement to shape or justify emergent educational policy and practice.

\section{Educational Research Capacity Building and International Transfer}

Recent years have seen the growth of academic and professional interest in the processes of research capacity building. A major stimulus for such activity in the UK and USA was sustained criticism directed at educational and social research dating from the mid 1990s. Authors such as Hargreaves (1996) in the UK and Kennedy (1997) in the USA initiated debates that suggested that too much educational research was too distant from the needs of policymakers, was lacking in a cumulative sense of authority, was insufficiently cost-effective and was too inaccessible for many stakeholders.

The response to this criticism took many forms, and in the UK it led to major investments in research strengthening and capacity building initiatives. These included the $f 40$ million Teaching and Learning Research Programme (TLRP), the generation of collaborative educational research networks, and the intensification of university level research assessment and evaluation processes (Gilroy \& McNamara 2009, p.321). To cite Menter and Murray (2009, p.315), '...in these times of accountability and audit, it should come as no surprise that there has been a great concern - some say obsession - with "capacity building"'.

In defining research capacity building, writers draw attention to the many dimensions and processes involved. There include the number and quality of experienced and qualified researchers, the range of skills involved, the nature and extent of the research infrastructure and facilities, the control, type and level available funding, and the sustainability of systems and processes. Pollard $(2008$, p.47) helps to conceptualise research capacity from a more 


\title{
Michael CROSSLEY
}

theoretical perspective by exploring the implications for capacity building on three different but mutually supportive levels:

\begin{abstract}
...a macro-level perspective upon the knowledge management system as a whole; a meso-level perspective upon a 'community' level of activity systems and institutions; and a micro-level focus on individuals' research capacity. The systemic perspective is abstract, considering the knowledge management system as a whole. The community perspective focuses upon activities, networks and outputs. The micro-perspective of the research capacity of individuals enables attention to be given to the working conditions, professional development opportunities, and career routes of those working within the field. An effective research capacity building strategy will need to provide a means of addressing research capacity at these different levels.
\end{abstract}

While such developments in the UK context have much to offer, other researchers such as Peters (2001), Onancea (2005), Hammersley (2008), and Watson (2011) draw attention to the dangers of educational research and research capacity building becoming too closely associated with policy-making processes and the goals of the state. Watson (2011, p.968) thus argues that neo-liberal principles of marketisation have moved the academy too close to a global economic model, 'that has brought us close to collapse'. These arguments are especially pertinent here, since they point to the dangers of marginalizing the role of the independent academic voice, and of undermining the place of the public intellectual. Perhaps even more pertinently, such cautionary voices also draw attention to the need to challenge some of the critics themselves, and to do more to acknowledge the importance of defending what Furlong refers to as 'a rich and diverse range of approaches to research, promoting debate about quality within different sub-communities and encouraging open discussion across epistemological and methodological boundaries,' (Furlong, 2004, p.343). This is especially important in cross-cultural and comparative arenas where differences in worldviews (see Hayhoe \& Pan, 2001) add to the complexities and ethical and political implications of research processes, methodologies and capacity-building initiatives.

We should, in sum, be careful not to let one conception of research and of research capacity building to overlydominate our thinking, especially where assumptions about the relative merits of different philosophical and epistemological paradigms, cultures, management structures and evaluation systems are within embedded. Moreover, it is argued that comparativists should apply their long held commitment to context sensitivity to the analysis of the uncritical international transfer of the processes and mechanisms of educational research capacity building. Without this, it is argued, there are very real dangers that educational research capacity within a diversity of international contexts may come to be shaped and 'built' in ways that may do more to maintain dependency and hegemony, than it will do to strengthen stakeholder ownership and voice, and to genuinely meet local needs.

To understand the magnitude of these issues, it is revealing to examine the global political economy of educational research in a little more detail. St Clair and Belzer (2007), for example, challenge the increasing dominance of powerful discourses that have come to dominate the shape of contemporary educational research cultures in the UK and the USA. In brief they argue that rather than improving the quality of educational research many of the 'structural transformations' that have been introduced over recent decades, 'can be seen as an attempt to promote market managerialism in educational research for political ends,' (St Clair \& Belzer, 2007, p.471). For these authors the continued globalisation of related research modalities warrants critical, comparative interrogation both at home and abroad. Providing what is, perhaps a clearer glimpse of these dangers, Vulliamy addresses an audience of comparativists directly by arguing that:

A concern for sensitivity to cultural context has been a key part of the field of comparative education in England - all the way from its pioneers...to current exponents... Such concern for cultural context also pervades sociological traditions underpinning the development of qualitative research... The challenge for future comparative and international researchers in education is to harness the symbiosis of these two traditions to resist the increasing hegemony of a positivist global discourse of educational research and policy-making (2004, p.277).

Building upon Vulliamy, it is argued here that while research capacity building is important within the field of international development, and within the comparative education constituency itself, the international transfer of currently dominant Western models and modalities deserves urgent and critical attention. In doing so, comparativists should ask whose capacity will be strengthened by new initiatives, whose values and approaches to research will be prioritized, whose modalities will be applied - and do these meet local needs, priorities and agendas? Do, for example, the expensive 'big science' approaches to social research increasingly favoured in the UK have the best potential to foster the strengthening of research capacity within low-income countries? And are the large-scale quantitative surveys increasingly promoted by international development agencies, and the currently fashionable international studies of student achievement, generating data that is context-sensitive enough to assist in the improvement of the quality of education in low-income countries with diverse cultural heritages and 


\section{COMPaRATIVE EdUCATION AND RESEARCH CAPACITy BUILDING}

traditions? Indeed, on a broader level, we should ask how we might best learn from comparative studies of education without falling prey to the dangers of uncritical international policy transfer.

With reference to my own research in Kenya and Tanzania there is much evidence to suggest that locallygrounded research, carried out by African researchers, perhaps in partnership with international colleagues, has much to offer if a greater proportion of educational reform initiatives are to be translated into successful practice. Studies of the implementation of the Primary School Management Project (PRISM) in Kenya (Crossley et al., 2005), for example, demonstrate how in-depth, qualitative field research played a central role in the shaping of this successful national in-service training programme for primary school head-teachers; and how research partnerships between specialist researchers and practitioners, insiders and outsiders, and local and international personnel were essential for generating crucial insights into grass-roots perspectives, problems and realities.

More recent research in Tanzania also demonstrates how research capacity building was supported by the development of long-standing international collaborative research partnerships. This work also highlighted the importance of such partnerships avoiding modalities that perpetuate the hegemony of the North (Barrett et al., 2011). In recognizing these issues and dilemmas, work like this is beginning to address the implications of uncritical international transfer in the research arena, but more work needs to be done. International research partnerships, for example, are increasingly encouraged by development agencies as a way of strengthening local engagement (Stephens, 2009; Rizvi, 2012). However, if such partnerships perpetuate imbalances in collaboration that prioritise Northern expertise and control, the simplistic transfer of fashionable or currently dominant approaches and modalities from the North to the South could help to reinforce what Tikly characterizes as the 'New Imperialism' (Tikly, 2004). For these reasons it is also important to support the publication of research findings in national and local journals and books if the power of prestigious international publishing houses is not to eclipse national academic publishing initiatives. More also needs to be done to support research from diverse cultural perspectives, as demonstrated by a recent Special Issue of the Journal Comparative Education on 'Educational Research in Confucian Heritage Cultures' (Evers, Katyal \& King, 2011). Learning from international experience is, as the comparative literature has long maintained, a more nuanced and subtle process if it is to prove successful.

With regard to the latter point, and to the impact of international studies of educational achievement, it is interesting to turn to an analysis of how PISA research findings are currently being used to shape the formulation of educational policy and practice in the UK. In a recent presentation to the Education World Forum held in London during 2011, Michael Gove, the current Secretary of State for Education, identified the head of the OECD's PISA studies as 'the most important man in the British education system' (2011). Here is clear evidence that one key policy-maker is looking directly to comparative research for policy guidance, arguing that to 'ignore' the PISA studies 'would be foolish' (ibid, see also Baird et al., 2011). While it is good for comparative studies to receive this attention, a close reading of the 2011 speech reveals that the Secretary of State's declared intention is to 'identify the best so we can emulate it', in the spirit of Jullien's positivistic approach to comparative data and to the transferability of 'best practice'. This type of selective borrowing and transplantation pays scant regard to more context-sensitive approaches to comparative research. Nor does it learn from Sadler's argument about the importance of 'the things outside the school' - the historical, political economic and cultural contexts within which education is conducted. Thus the UK Secretary of State's attention is drawn to emulating educational policy and practice in the 'top' performing systems according to PISA. In the European region this means Finland, and in South-east Asia his attention is drawn to Hong Kong and Singapore. While this is not the place to develop a detailed critique of these education systems and the related arguments, there is a rapidly growing body of comparative research that demonstrates how the high student achievement scores attained in the latter two systems are closely connected to the all-pervasive amount of extra, out-of-school, private coaching that is provided by the 'Shadow Education System' (Bray, 2009), and that this is backed up by the societal influence of Confucian heritage cultures. In Michael Sadler's terms it is 'the things outside the schools' that may make the difference. From this perspective, the lessons for the UK to learn from school experience in Hong Kong and Singapore may be very different from those that are now being actively promoted in educational policy debates by the present UK government. While this interpretation may be contested, what this example does demonstrate is the importance of acknowledging the value and importance of different approaches to educational, social and comparative research - and above all, the importance of context sensitivity at multiple levels of education and society. Context does, indeed, matter...more than many policy-makers and educational researchers realise (Crossley, 2010).

This is not to suggest that context is all-important, nor is it to disregard the very real contributions to educational and comparative research that are being made by the theoretical, statistical or 'big science' approaches and modalities (see, for example, Bray et al., 2007). Rather, the case being made here is for the potential of different approaches to be realistically acknowledged where they are appropriate, and for initiatives designed so support research capacity building to promote respect for, training in and funding for that 'rich and diverse range of approaches' called for by authors such as Furlong. In Malaysia, for example, doctoral research recently carried out by Mohd Asri (2012) on the development and implementation of the nationwide Clusters of Excellence innovation, 


\section{Michael CRossley}

applied many of the comparative principles articulated above in carrying out detailed, qualitative case studies of participating schools. This documents differences encountered in their experiences as they worked towards successful implementation. Findings from this qualitative, context-sensitive research complement statistical data generated by the Ministry of Education, and helps to identify problems encountered and potential ways forward. This very new study could also be used to contribute to the future evaluation of this important innovation. Of particular note in Mohd Asri's findings is the way in which the different environmental and cultural contexts of the case study schools have influenced their interpretation of and success with the Clusters of Excellence initiative. On a broader level, this insightful comparative study examines the nature and origins of the Clusters of Excellence policy. This considers the extent to which external models and national plans were combined in the development of an initiative designed to enhance the quality of education in Malaysia. From a theoretical perspective, the study draws upon and applies Phillips and Ochs's (2004) comparative model of policy borrowing in education. This is, therefore, an example of locally initiated and led research that bridges the worlds of theory, policy and practice (Crossley, 2008) in ways that are inspired by the principles of modern, context sensitive, comparative research in education. In doing so, the author also makes a personal contribution to the strengthening of this form of educational research capacity in his own education system.

\section{Conclusions}

It is in the above spirit that the case is made for increased attention to be given to research capacity building in educational research, comparative studies and the broader processes of international development co-operation. Comparative and international research in education is especially well placed to contribute to this process given its context sensitivity and direct, and critical, engagement with the dilemmas generated by the international transfer of educational policy and practice. In the current international climate, it is argued that powerful global forces and agendas are, once again, increasingly prioritising, and internationalising, modalities of educational and social research that are underpinned by positivistic assumptions and orientations. Within the field of comparative education this is both a familiar and a revealing story. The global impact of large-scale international surveys of student achievement helps to legitimize such developments - and there is rapidly increasing evidence of the dramatic impact of such survey and related league table findings upon educational policy and practice worldwide.

While there are advances to be gained from these initiatives, much theoretical and methodological literature in the field of comparative and international education has long pointed to the limitations of the search for 'best practice', especially in cross-cultural contexts. Comparative research can certainly inspire and inform developments elsewhere, but we should not expect it to provide a fixed blueprint for further implementation. As Stenhouse (1979, pp.5-6) maintains, comparative research in education should deal 'in insight rather than law as a basis for understanding', and insights derived in this way can then help to 'tutor our judgment' with regard to the possible adaptation or modification of policy for application elsewhere.

If educational research capacity is to be strengthened in any system, then one key lesson from the comparative experience is that a diversity of approaches to research deserve attention and support - and that efforts to use research to inform and guide educational innovation respond especially well to locally grounded, context sensitive approaches, strategies and paradigms. Lewin and Akeampong's (2009) large-scale statistically informed and longitudinal research on access to basic education in sub-Saharan Africa thus acknowledges that 'the real problems of continuing to improve meaningful access to education...are becoming highly differentiated and reflect diverse contexts' (Lewin, 2007, p.597). Demonstrating how different approaches to educational research can be mutually supportive, Lewin thus also suggests that globally agreed:

...Goals and targets can help but only if they are adapted to circumstances, more varied in kind, more linked to concerns for equity, quality and valued outcomes, and owned more by those who are presumed to benefit (Lewin, 2007, p.597).

This points to the importance of both comparative research and to the need for greater local capacity, engagement and control. In the light of this analysis I am especially pleased to support the inauguration of a new Centre for Research in International and Comparative Education (CRICE) at the University of Malaya. This has the potential to make a major contribution to the development of Malaysian educational policy and practice in future years; to play a central role in strengthening national educational research capacity; to foster the development of locally grounded academic publishing; and to make a distinctively Malaysian contribution to the field of comparative and international research in education, and to international educational scholarship in general.

\section{Acknowledgements}




\section{COMPARATIVE EdUCATION AND RESEARCH CAPACITY BUILDING}

Thanks go to Terra Sprague, University of Bristol, for valuable feedback and assistance in the finalisation of this article. Early sections of the paper draw upon and extend material from the following two articles:

Crossley, M., \& Watson, K. (2009) Comparative and international research in education: Policy transfer, context sensitivity and professional development. Oxford Review of Education, 35(5), 623-649.

Crossley, M. (2011). Strengthening educational research capacity in small states. In M. Martin \& M. Bray (Eds.) Tertiary Education in Small States: Planning in the Context of Globalization. UNESCO/IIEP: Geneva.

\section{References}

Baird, J., Johnson, S., Stobart, G., Yu, G., Isaacs, T., \& Sprague, T. (2011). Policy effects of PISA, for Pearson UK 2011. Available at http://oucea.education.ox.ac.uk/wordpress/wp-content/uploads/2011/10/Policy-Effects-of-PISAOUCEA.pdf.

Barrett, A.M., Crossley, M. \& Dachi, H.A. (2011). International collaboration and research capacity building: Learning from the EdQual experience. Comparative Education, 47(1), 25-43.

Beech, J. (2006). Redefining educational transfer: International agencies and the (re)production of educational ideas. In J. Sprogoe \& T. Winther-Jensen (Eds.). Identity, education and citizenship: Multiple interrelations. Frankfurt am Main: Peter Lang.

Bray, M. \& Thomas, R.M. (1995). Levels of comparison in educational studies: Different insights from different literatures and the value of multi-level analysis. Harvard Educational Review, 65(4), 472-490.

Bray, M. (2009). Confronting the shadow education system: What government policies for what private tutoring? Paris: UNESCO.

Bray, M., Adamson, B. \& Mason, M. (Eds.) (2007). Comparative education research: Approaches and methods. Hong Kong: Springer and Comparative Education Research Centre, The University of Hong Kong.

Crossley, M. (1984). Strategies for curriculum change and the question of international transfer. Journal of Curriculum Studies, 16(1), 75-88.

Crossley, M. (1999). Reconceptualising comparative and international education. Compare, 29(3), 249-267.

Crossley, M. (2008). Bridging cultures and traditions for educational and international development: Comparative research, dialogue and difference. International Review of Education, 54(3-4), 319-336.

Crossley, M. (2010). Context matters in educational research and international development: Learning from the small states experience. Prospects, 40(4), 421-429.

Crossley, M. (2011). Strengthening the development of educational research capacity in small states. In M. Martin \& M. Bray (Eds.). Tertiary education in small states: Planning in the context of globalisation. Paris: UNESCO/IIEP.

Crossley, M., Herriot, A., Waudo, J., Mwirotsi, M., Holmes, K., \& Juma, M. (2005). Research and evaluation for educational development: Learning from the PRISM experience in Kenya. Oxford: Symposium Books.

Crossley, M. \& Tikly, L. (2004). Postcolonial perspectives and comparative and international research in education: A critical introduction. Comparative Education, 40(2), 147-156.

Crossley, M. \& Vulliamy, G. (Eds.) (1997). Qualitative educational research in developing countries. London: Garland Publishing, Inc.

Crossley, M. \& Watson, K. (2003). Comparative and international research in education: Globalisation, context and difference. London: Routledge.

Crossley, M. \& Watson, K. (2009). Comparative and international education: Policy transfer, context sensitivity and professional development. Oxford Review of Education, 35(5), 633-649.

Evers, C.W., King, M. \& Katyal, K.R. (Eds.) (2011). Educational research in Confucian heritage cultures. Comparative Education, 47, (3: Special Issue).

Fraser, S.E. (1964). Jullien's plan for comparative education 1816-1817. New York: Bureau of Publications, Teachers' College, Columbia University.

Furlong, J. (2004). BERA at 30: Have we come of age? British Educational Research Journal, 30(3), 343-358.

Furlong, J. \& Lawn, M. (2011). Disciplines of education: Their role in the future of education research. London: Routledge.

Gilroy, P. \& McNamara, O. (2009). A critical history of research assessment in the United Kingdom and its post-1992 impact on education. Journal of Education for Teaching, 35(4), 321-335.

Gove, M. (2011). Education for economic success. Available at http://www.education.gov.uk/emailer/inthenews/speeches/a0072274/michael-gove-to-the-education-worldforum?if=1 [accessed January 13, 2012].

Grek, S., Lawn, M., Lingard, B., Ozga, J., Rinne, R., Segerholm, C., \& Simola, H. (2009). National policy brokering and the construction of the European education space in England, Sweden, Finland and Scotland. Comparative 


\section{Michael Crossley}

Education, 45(1), 5.

Hammersley, M. (2008). Troubling criteria: A critical commentary on Furlong and Oancea's framework for assessing educational research. British Educational Research Journal, 34(6), 747-762.

Hargreaves, D.H. (1996). Teaching as a research-based profession: Possibilities and prospects. London: The Teacher Training Agency.

Hayhoe, R. \& Pan, J. (Eds.) (2001). Knowledge across cultures: A contribution to dialogue among civilizations. Hong Kong: Comparative Education Research Centre, University of Hong Kong.

Higginson, J.H. (Ed.) (1979). Selections from Michael Sadler: Studies in world citizenship. Liverpool: Dejall \& Meyorre. Holmes, B. (1965). Problems in education. London: Routledge \& Kegan Paul.

Jullien, M. (1817/1962). Esquisse d'un ouvrage sur l'éducation comparée. Paris: De Fain. Reprinted by Genéve: Bureau International d'Éducation.

Kandel, I.L. (1933). Studies in comparative education. Boston, MA: Houghton and Mifflin.

Kennedy, M. (1997). The connection between research and practice. Educational Researcher, 26(7) 4-12.

Lewin, K. (2007). Diversity in convergence: Access to education for all. Compare, 37(5), 577-599.

Lewin, K. \& Akyeampong, K. (Eds.) (2009). Access to education in sub-Saharan Africa. Special Issue of Comparative Education, 45(2).

Masemann, V., Bray, M. \& Manzon, M. (Eds.) (2007). Common interests, uncommon goals: Histories of the world Council of Comparative Education Societies and its members. Hong Kong: The University of Hong Kong and Springer.

McGrath, S. (2001). Research in a cold climate: Towards a political economy of British international and comparative education. International Journal of Educational Development, 21(5), 391-400.

Menter, I. \& Murray, J. (2009). Capacity building in teacher education research. Journal of Education for Teaching, 35(4), 315-319.

Mohd Asri, M.N. (2012). The Malaysian clusters of excellence policy: A multi-site case study. Unpublished doctoral thesis. UK: University of Bristol.

Noah, H.J. \& Eckstein, M.A. (1969). Toward a science of comparative education. London: Macmillan.

O'Sullivan, M. (2008). Comparative education in teacher education in the UK and Ireland. In: C. Walhuter et al. Comparative education at universities world-wide (2nd edn.) Sofia: Bureau for Educational Services, pp. 136142.

Oancea, A. (2005). Criticisms of educational research: Key topics and levels of analysis. British Educational Research Journal, 31(2), 157-183.

OECD (2001). Knowledge and skills for life: First results from the OECD Programme for International Student Assessment (PISA 2000). Available at http://www.pisa.oecd.org/dataoecd/44/53/33691596.pdf [Accessed 14 January 2012].

OECD (2004). Learning for tomorrow's world: First results from PISA 2003. Available at http://www.pisa.oecd.org/document/55/0,3746,en_32252351_32236173_33917303_1_1_1_1,00.html.

[Accessed 14 January 2012].

OECD (2007). PISA 2006 science competencies for tomorrow's world. Available at http://www.oecd.org/document/2/0,3746,en_32252351_32236191_39718850_1_1_1_1,00.html [Accessed 14 January 2012].

OECD (2010). PISA $2009 \quad$ Available http://www.oecd.org/document/61/0,3746,en_32252351_32235731_46567613_1_1_1_1,00.html [Accessed 14 January, 2012].

Peters, M. (2001). National policy constructions of the knowledge economy: Towards a critique. Journal of Educational Enquiry, 2(1), 1-22.

Phillips, D., \& Ochs, K. (2004). Researching policy borrowing: some methodological challenges in comparative education. British Educational Research Journal, 30(6), 773-784.

Pollack, E. (1993). Isaac Leon Kandel (1881-1965). Prospects, 23(314), 775-787.

Pollard, A. (2008). Quality and capacity in UK E=educational research: Report of the first SFRE Meeting. Harrogate: Strategic Forum for Research in Education.

Postlethwaite, T.N. (1999). International studies of educational achievement: Methodological issues. Hong Kong: The University of Hong Kong.

Rappleye, J., Imoto, Y. \& Horiguchi, S. (2011). Towards "thick description" of educational transfer: Understanding a Japanese institution's "impact" of European language policy. Comparative Education, 47(4), 411-432.

Rizvi, S. (Ed.) (2012). Multidisciplinary approaches to educational research. New York: Routledge.

St Clair, R. \& Belzer, A. (2007). In the market for ideas: How reforms in the political economy of educational research in the US and UK promote market managerialism. Comparative Education, 33(4), 471-488. 


\section{COMPARATIVE EdUCATION AND RESEARCH CAPACITy BUILDING}

Stenhouse, L. (1979). Case study in comparative education: Particularity and generalisation. Comparative Education, 15(1), 5-10.

Stephens, D. (2009). Higher education and international capacity building: Twenty-five years of higher education links. Oxford: Symposium Books.

Tikly, L. (2004). Education and the new imperialism. Comparative Education, 40(2), 173-198.

UNESCO (2009). EFA Global Monitoring Report 2010: Reaching the marginalised. Oxford: Oxford University Press.

Vulliamy, G. (2004). The impact of globalisation on qualitative research in comparative and international education. Compare, 34(3), 261-284.

Watson, C. (2011). Accountability, transparency, redundancy: Academic identities in an era of "excellence." British Educational Research Journal, 37(6), 955-971. 